\title{
HISTORICISMO Y TEMPORALIDADES PLURALES EN LOS DESENCUENTROS Y REENCUENTROS ENTRE GRAMSCI Y ALTHUSSER
}

\section{HISTORICISM AND PLURAL TEMPORALITIES IN THE DISENCOUNTERS AND REENCOUNTERS BETWEEN GRAMSCI AND ALTHUSSER}

\author{
Alfonsina Santolalla ${ }^{1}$ \\ Consejo Nacional de Investigaciones Científicas y Técnicas (CONICET), \\ Universidad de Córdoba (UNC), Argentina
}

Recibido: 5 mayo 2020

Aceptado: 15 julio 2020

Resumen: En el presente artículo me propongo trabajar sobre la presencia del concepto de "historicismo absoluto" en los Cuadernos de la cárcel de Gramsci, y sobre las críticas que Althusser le confirió al mismo. Sostengo que la noción de "historicismo absoluto" permite tematizar el problema de la historia y del tiempo en ambos autores, e intentaré mostrar que es justamente en ese terreno en que es posible trazar hoy caminos para el reencuentro entre Gramsci y Althusser a partir del reconocimiento de que el uno y el otro han desarrollado -a su manera- modelos de temporalidad plural.

Palabras clave: Historicismo Absoluto, Temporalidades Plurales, Materialismo Histórico, Marxismo, Inmanencia.

\begin{abstract}
In this article I intend to work on the presence of the concept of "absolute historicism" in Gramsci's Prison Notebooks, and on the criticism that Althusser conferred on it. I affirm that the notion of "absolute historicism" allows us to thematize the problem of history and time in both authors, and I will try to show that it is precisely in this terrain that it is possible to trace ways today for the reunion between Gramsci and Althusser based on recognition that the one and the other have developed - in their own way - models of plural temporality.
\end{abstract}

Key words: Absolute Historicism, Plural Temporalities, Historical Materialism, Marxism, Immanence.

1. Becaria doctoral del Consejo Nacional de Investigaciones Científicas y Técnicas (Argentina). Licenciada y Profesora en Filosofía por la Universidad Nacional de Córdoba, asn.713@gmail.com 


\section{Introducción}

Durante la segunda mitad del siglo XX los respectivos legados teóricos de Antonio Gramsci y Louis Althusser se leyeron como discursos antagónicos. La razón principal es que el filósofo francés fue categórico en su oposición a ciertos desarrollos conceptuales atribuidos al pensador italiano, quien escribió gran parte de su obra encarcelado por el régimen fascista. La discusión cuenta con una multiplicidad de aristas, y lejos de poder abordarlas a todas, en el presente artículo trabajaré en particular sobre la presencia del concepto de "historicismo absoluto" en los Cuadernos de la cárcel de Gramsci, y sobre las críticas que Althusser le confirió al mismo. La noción de "historicismo absoluto" constituye una de las nociones más aludidas en el debate que Althusser inició con Gramsci al percibir ciertos elementos del hegelianismo especulativo en su filosofía. Considero que es interesante el abordaje de ese debate debido a que permite tematizar el problema de la historia y del tiempo en ambos autores, y lo que intentaré mostrar es que es justamente en ese terreno en que es posible trazar hoy caminos para el reencuentro entre Gramsci y Althusser a partir del reconocimiento de que el uno y el otro han desarrollado -a su manera- modelos de temporalidad plural.

Para lograr hacer un análisis del modo en que la perspectiva gramsciana y la althusseriana pueden encontrarse -a pesar de sus desencuentros- en el desarrollo de sus respectivas concepciones de la temporalidad como un fenómeno plural, sostengo que es menester realizar dos operaciones complementarias. Por un lado, resulta importante realizar una exégesis de los Cuadernos de la cárcel para comprender hacia dónde apunta la incorporación de la idea de "historicismo absoluto", un concepto proveniente del filósofo especulativo Benedetto Croce - a quien Gramsci construye durante todas sus reflexiones como su principal adversario teórico. Por otro lado, es necesario contextualizar las críticas de Althusser al "historicismo absoluto" gramsciano para comprenderlas en su complejidad.

La hipótesis que guía esta investigación sostiene que en los Cuadernos de la cárcel Gramsci produce una maniobra conceptual que demuestra -a diferencia de lo que creía Althusser- que el concepto de "historicismo absoluto" reviste un fuerte carácter anti-especulativo, al punto de constituir una noción de central importancia para la construcción de un modelo de temporalidad plural. He decidido denominar a dicha maniobra "reinvención gramsciana de la inmanencia", y la misma consiste en la asociación que Gramsci realiza entre el concepto de inmanencia y el de "terrenalidad del pensamiento" -una expresión extraída de las Tesis sobre Feuerbach de Marx- para afirmar la existencia de un vínculo intrínseco entre la teoría y la práctica. El objetivo que me propongo aquí consiste, 
por una parte, en corroborar la hipótesis mencionada. Y, por otra parte, en mostrar que la crítica de Althusser al "historicismo absoluto" gramsciano no consideró la asociación entre dicho concepto y la "reinvención gramsciana de la inmanencia" a la que aquí me refiero, y que, en consecuencia, las teorías en torno al tiempo y la historia atribuidas a estos dos grandes autores se han posicionado en sus respectivas antípodas, cuando en realidad existe entre ellas una importante coincidencia en la concepción de la temporalidad como plural y de la historia como no-lineal.

En aras de la consecución del objetivo mencionado, las etapas de este artículo se organizan de la siguiente manera. En primer lugar, mostraré el modo en que el desarrollo del concepto gramsciano de "historicismo absoluto" se encuentra directamente relacionado con la decisión explícita de Gramsci de distanciarse, desde el comienzo de su trabajo en los Cuadernos, de los trabajos teóricos de Benedetto Croce y Nikolái Bujarin. En segundo lugar, detallaré cuáles son las características que el concepto gramsciano de "historicismo absoluto" muestra en su propio texto fuente. En tercer lugar, realizaré una breve recapitulación de los pormenores de la crítica de Althusser al "historicismo absoluto" gramsciano. Por último, desarrollaré la idea de que es posible encontrar tanto en Althusser como en Gramsci indicios sobre existencia de temporalidades plurales, y de que ese hecho constituye un punto de encuentro entre ambos autores desde una perspectiva actual.

\section{Críticas gramscianas a Croce y Bujarin}

En la primera página del Cuaderno 1 de los Cuadernos de la cárcel, Gramsci escribe una lista de los temas principales a estudiar en el marco de su trabajo en el encierro, entre los que se encuentra el título "Teorías de la historia y de la historiografía". ${ }^{2}$ Peter Thomas ${ }^{3}$ señala que ese tema en particular es desarrollado en el Cuaderno 4, durante el mismo período de tiempo en que Gramsci traduce las Tesis sobre Feuerbach de Marx. Allí Gramsci dice: «El materialismo histórico, tal como es, es el aspecto popular del historicismo moderno". ${ }^{4}$ Es posible decir que se refiere, por una parte -y siguiendo a Thomas en este punto-, a que el materialismo histórico no proviene de ninguna corriente a la que pueda reducirse completamente, sino que es el resultado de la conjunción compleja entre muchas tradiciones, entre ellas la del historicismo, a la que perteneció Hegel. A mi juicio,

2. Gramsci, A.: Cuadernos de la Cárcel, México D.F.: Era, 1981, C1 "Temas principales".

3. Cf. Thomas, P.: The Gramscian Moment: Philosophy, Hegemony and Marxism, Leiden-Boston: Brill, 2009, p. 243.

4. Gramsci, A.: op. cit., C4 §3.

Thémata. Revista de Filosofía N62 (2020) pp.: 105-124. 
la insistencia de Gramsci en torno a la idea de que el materialismo histórico es deudor de una multiplicidad de tradiciones -y no sólo una- responde a un reconocimiento de su parte de la incorporación de elementos de diferentes tradiciones que el propio Marx realizó en su obra. Por otra parte, en la cita referida, Gramsci está indicando que el materialismo histórico es "el aspecto popular" del historicismo porque se trata de un desarrollo teórico que reconoce el carácter ideológico de toda historia, y en eso se diferencia del resto de los historicismos. Esta última idea está directamente relacionada con los señalamientos que Gramsci realiza, simultánea y complementariamente, a la filosofía de Benedetto Croce y al materialismo de Nikolái Bujarin. Detallaré brevemente en qué consisten las críticas gramscianas a ambos autores en relación al historicismo.

El Ensayo popular de sociología $a^{5}$ de Bujarin -originalmente publicado en 1921-, además de ser criticado por Gramsci por referirse al uso del término inmanencia en Marx como meramente metafórico, ${ }^{6}$ es señalado por el italiano debido al tipo de materialismo que allí se construye. «Gramsci argumenta que Bujarin había reducido la dimensión filosófica del marxismo a una versión del vulgar y tradicional materialismo del siglo XVIII». ${ }^{7}$ En otras palabras, Gramsci observa que la propuesta sociológica de Bujarin recae en un materialismo determinista y pre-marxista, ya que no sólo establece una serie de leyes filosóficas que parecen ser a-históricas, sino que además ignora la novedad teórica más importante -a criterio de Gramsci- producida a partir de Marx: el señalamiento del carácter histórico y político de todo planteo filosófico-teórico. Cuando se lee la afirmación de Gramsci sobre el materialismo histórico como "historicismo popular" a la luz de su señalamiento sobre que el materialismo de Bujarin carece de auto-reflexividad al ponerse por fuera de la historia para formular sus leyes -lo cual impide que comprenda su propia historicidad-, es posible pensar que el objetivo gramsciano es construir un materialismo histórico opuesto a dicha sociología, y que el concepto de "historicismo" sirve a dichos fines.

Por su parte, la crítica del historicismo crociano se encuentra en el Cuaderno 8 -escrito en la misma etapa de trabajo que el Cuaderno 4. Allí

5. Bujarin, N.: Teoría del materialismo histórico. Ensayo popular de sociología marxista. Córdoba: Ediciones Pasado y Presente, 1972.

6. Frente a la postura de Bujarin de que en Marx el uso del término "inmanencia" no puede ser más que metafórico (Bujarin, 1974: 45), Gramsci sostiene que en Marx hay un uso consciente y profundo del término inmanencia, y que si se quiere nombrar a ese uso como "metafórico" hay que considerar que es igual de metafórico que el resto de los usos del lenguaje, ya que "el lenguaje es al mismo tiempo es una cosa viva y un museo de fósiles de la vida y las civilizaciones pasadas" (Gramsci, 1981: C4, §17).

7. Cita traducida del inglés. Thomas, P.: op. cit., p. 252.

Thémata. Revista de Filosofía No62 (2020) pp.: 105-124. 
Gramsci señala que el historicismo "historiográfico" de Croce es de carácter especulativo e ideológico.

Croce trata siempre de poner de relieve cómo él, en su actividad de pensador, ha procurado "expulsar" del campo de la filosofía todo residuo de teología y de metafísica, hasta llegar a negar todo "sistema" filosófico, presentando la filosofía como solución de los problemas filosóficos que el desarrollo histórico presenta e impone en su desarrollo. ¿Pero acaso cada filosofía "especulativa” no es ella misma una teología y una metafísica? Este "residuo" no es un residuo, es un "todo", es todo el método del filosofar, y por esto toda afirmación de "historicismo" es vana, porque se trata de "historicismo" especulativo, del "concepto" de historia y no de la historia. ${ }^{8}$

$\mathrm{Al}$ igual que sucede con Bujarin, en opinión de Gramsci Croce no reconoce el carácter ideológico e histórico de su propia filosofía. Sin embargo, en esta reconstrucción de las discusiones que entabla Gramsci en torno al historicismo en general, es importante detenerse específicamente en las implicancias del "historicismo absoluto" crociano. La crítica gramsciana a Croce reviste un interés particular para el presente artículo, ya que permite delinear los términos en que Gramsci construye su propia idea de "historicismo absoluto".

El Cuaderno 10, escrito en la segunda etapa de producción de los Cuadernos -en la que Gramsci re-escribe, ordena y amplía los de la primera-, está dedicado casi por completo a Croce. Para Gramsci, la filosofía crociana constituye un "historicismo absoluto" porque establece una "absoluta inmanencia" del Espíritu respecto del mundo, y considera que eso se refleja en una unión también inmanente entre filosofía e historia. ${ }^{9}$ Sin embargo, el análisis de Gramsci permite observar que este vínculo inmanente que Croce instaura entre historia y filosofía -como unidad o identificación entre ambos términos- termina siendo contradicho por el hecho de que, a la vez, conserva la idea de Espíritu, que -en continuidad con la filosofía hegeliana- se caracteriza por existir por fuera del plano de la historicidad. Para Gramsci, la preservación del Espíritu absoluto impide el desarrollo real de un historicismo porque le da a la filosofía un carácter especulativo: como dice en la cita anterior, ni siquiera se trata de un residuo de metafísica, sino que la totalidad de la filosofía de Croce es metafísica y como tal se encuentra apartada de la historicidad. Al mismo tiempo, la relación inmanente entre filosofía e historia que Croce plantea no tiene las características de una "terrenalidad del pensamiento" como la que piensa Gramsci -como fue mencionado en la Introducción- para definir inmanencia como unidad entre teoría y práctica. Por el contrario, al usar el término inmanencia Croce incurre según Gramsci- en una contradicción: debido a que pretende establecer una

8. Gramsci, A.: op. cit., C8 §224.

9. Cf. Thomas, P.: op. cit., 267.

Thémata. Revista de Filosofía N62 (2020) pp.: 105-124. 
filosofía exenta de elementos ideológicos por suponerlos irremediablemente religiosos, no construye un vínculo inmanente sino una distancia cualitativa entre filosofía e ideología. Gramsci señala que los términos filosofía e historia nunca pueden identificarse de forma inmanente en el pensamiento de Croce, pues la historia es el campo de la práctica, de la lucha de clases y como tal, de las luchas ideológicas. ${ }^{10} \mathrm{El}$ resultado de esto es la constatación de que Croce puede reconocer el carácter ideológico de otras metafísicas y de la teología, pero no de su propia filosofía. La identificación crociana entre filosofía e historia, concluye Gramsci, carece de una dimensión de la política. ${ }^{11}$

Para Gramsci, en síntesis, tanto Bujarin como Croce presuponen una idea especulativa del conocimiento - materialista e idealista, respectivamente. Frente a esto, procura afirmar que no existe -como creía Croce- diferencia cualitativa entre filosofía e ideología, sino que entre ambos términos hay sólo una distinción cuantitativa.

es filosofía la concepción del mundo que representa la vida intelectual y moral (catarsis de una determinada vida práctica) de un grupo social entero concebido en movimiento y visto por lo tanto no sólo en sus intereses actuales e inmediatos, sino también en aquellos futuros y mediatos; es ideología cada concepción particular de los grupos internos de la clase que se proponen ayudar a la resolución de problemas inmediatos y circunscritos. ${ }^{12}$

Esto quiere decir que la filosofía no difiere sustancialmente -o cualitativamente- de otras concepciones ideológicas del mundo, sino sólo en términos cuantitativos. Debido a su carácter crítico, la filosofía abarca problemas que exceden a los intereses inmediatos de un grupo social determinado; y, por su parte, la mera ideología es todo aquello que se atiene con exclusividad a lo inmediato, a lo puntualmente localizado. Al establecer una diferencia cuantitativa entre filosofía y otras formas de ideología -como el sentido común o la religión- Gramsci indica que el carácter distintivo de la filosofía es el de ser una concepción del mundo elaborada de manera coherente y crítica. Pero que, en última instancia, la filosofía reviste siempre un carácter ideológico, debido a que se trata de una concepción del mundo proveniente de una determinada coyuntura, en un determinado momento de la historia. Para Gramsci, la unidad inmanente que existe entre -todo tipo de- teoría

10. Sobre este problema, Gramsci se pregunta: «Si por religión se ha de entender una concepción del mundo (una filosofía) con una norma de conducta correspondiente, ¿qué diferencia puede existir entre religión e ideología (o instrumento de acción) y en último análisis, entre ideología y filosofía? (...) Y si la filosofía y la moral son siempre unitarias, ¿por qué la filosofía debe ser lógicamente anterior a la práctica y no viceversa? ¿O no es un absurdo semejante planteamiento y no debe concluirse que "historicidad" de la filosofía no significa otra cosa que su "practicidad”?» Gramsci, A.: op. cit., C10II §31.

11. Cf. Ídem.

12. Ibíd., C10I §10.

Thémata. Revista de Filosofía №62 (2020) pp.: 105-124. 
y práctica, hace que cualquier concepción del mundo o expresión del pensamiento tenga carácter práctico, ya sea que se presente como ideología o que se elabore con cierta sistematicidad crítica como filosofía.

\section{Sobre el "Historicismo absoluto" en los Cuadernos de la cárcel}

Atendiendo a la noción gramsciana de inmanencia definida como relación intrínseca entre teoría y práctica, y a las críticas a Croce y Bujarin que he repasado hasta aquí, es posible afirmar que el historicismo que aparece desarrollado en los Cuadernos busca desmarcarse de toda filosofía especulativa. El historicismo gramsciano hace énfasis en la cuestión de la historicidad, del carácter práctico y situado de todo pensamiento. La siguiente cita lo expresa claramente, a partir de la lectura de las Tesis sobre Feuerbach:

La tesis XI: «Los filósofos no han hecho más que interpretar en diversos modos el mundo; pero de lo que se trata es de transformarlo", no puede ser interpretada [como pensó Croce] como un gesto de repudio a toda clase de filosofía, sino sólo de fastidio por los filósofos y su papagayismo y la enérgica afirmación de una unidad entre teoría y práctica. (...) Esta interpretación de las Glose al Feuerbach como reivindicación de unidad entre teoría y práctica, y por lo tanto como identificación de la filosofía con lo que Croce llama ahora religión (concepción del mundo con una norma de conducta correspondiente) (...) por lo demás no es más que la afirmación de la historicidad de la filosofía hecha en los términos de una inmanencia absoluta, de una "terrenidad absoluta". ${ }^{13}$

Gramsci retoma el concepto "historicismo absoluto" proveniente de Croce, aunque -como es evidente por lo hasta aquí reconstruidotransforma radicalmente su contenido. El problema para el abordaje de la versión gramsciana del concepto radica en que se trata de una noción difícil de rastrear: según Thomas, ${ }^{14}$ la expresión "historicismo absoluto" aparece explícitamente sólo tres veces en los Cuadernos. La primera y la segunda referencias literales a este concepto fueron escritas durante la segunda etapa de producción de los Cuadernos de la cárcel. La primera se remonta a una fecha entre febrero y marzo de 1932, y dice:

Para la compilación de una introducción o iniciación al estudio de la filosofía habrá que tener en cuenta algunos elementos preliminares: (...) $6^{\circ}$ ) Trascendencia, inmanencia, historicismo absoluto. Significado e importancia de la historia de la filosofía. ${ }^{15}$

Como se puede ver, "historicismo absoluto" e inmanencia se plantean como estrechamente relacionados. La segunda mención fue escrita entre julio

13. Ibid., C10II §31.

14. Thomas, P.: op. cit., p. 243.

15. Gramsci, A.: op. cit., C8 § 204.

Thémata. Revista de Filosofía No62 (2020) pp.: 105-124. 
y agosto de 1932, rezando: "La filosofía de la praxis es el "historicismo" absoluto, la mundanización y terrenalidad absoluta del pensamiento, un humanismo absoluto de la historia." ${ }^{16}$ Este pasaje es probablemente el más conocido al respecto y es el que dio pie a la crítica que -como mostraré a continuación- formula Louis Althusser, considerado el principal crítico del historicismo gramsciano. La tercer referencia es de junio o julio de 1933, luego de que Gramsci atravesara una importante crisis de salud y cuando se encontraba en la tercer -y última- etapa de escritura de los Cuadernos; allí dice: "El inmanentismo hegeliano se vuelve historicismo; pero es historicismo absoluto sólo con la filosofía de la praxis, historicismo absoluto o humanismo absoluto". ${ }^{17}$

$\mathrm{Al}$ tratarse de un concepto que sólo aparece en tres frases sin ulterior desarrollo considerable, la noción gramsciana de "historicismo absoluto" ha sido fuente de grandes interrogantes pero también de importantes especulaciones en torno a su significado. Desde mi punto de vista, es posible afirmar que, por la disposición del término en los Cuadernos y en consideración de la crítica del "historicismo absoluto" de Croce, el "historicismo absoluto" gramsciano constituye un concepto fuertemente ligado a los de inmanencia -como terrenalidad del pensamiento, o unidad inmanente entre teoría y práctica- y filosofía de la praxis -referente a la afirmación del carácter práctico e histórico de la realidad, y asociado a la crítica del carácter especulativo de las filosofías con las que se encontraba discutiendo. De manera sintética, puedo decir que cuando Gramsci hace uso del término "historicismo absoluto", de fondo existe una afirmación del carácter práctico e histórico de todos las formas de pensamiento, por el vínculo inmanente que para el autor existe entre teoría y práctica. Thomas comenta que si bien no se trata de un concepto que Gramsci haya desarrollado de manera acabada,

la exploración de todos los potenciales de una práctica filosófica y política "absolutamente historicista" es uno de los desafíos más apremiantes y una de las oportunidades más fructíferas para el desarrollo y la revitalización del marxismo contemporáneo. ${ }^{18}$

Además de sostener esta tesis, Thomas menciona el interés de autores como Badaloni, Spiegel y Tosel en la categoría de "historicismo absoluto" como uno de los conceptos centrales para comprender la potencialidad del pensamiento de Gramsci. Pero todas estas lecturas sólo fueron posibles una vez que salió a la luz la edición crítica y cronológica de los Cuader-

16. Ibid., C11 27 .

17. Ibid., $\mathrm{C} 15 \S 61$.

18. Cita traducida del inglés. Thomas, P.: "Historicism, absolute" en Historical Materialism 15, 2007, p. 255.

Thémata. Revista de Filosofía No62 (2020) pp.: 105-124. 
nos de la cárcel en 1975, pues, como mostraré en lo que sigue, durante la mayor parte de la recepción de la obra de Gramsci en el siglo XX el concepto gramsciano de "historicismo absoluto" fue leído de manera completamente crítica.

\section{Críticas althusserianas al "Historicismo absoluto" de Gramsci}

Existen muchas reflexiones sobre las diferencias entre las lecturas e interpretaciones de los Cuadernos de la cárcel que se produjeron a partir de la publicación de la primera edición (encargada por Palmiro Togliatti en 1948) y las que aparecieron luego de la publicación de la edición crítica de 1975 (edición a cargo de Valentino Gerratana). Aquí me interesa retomar la de Thomas, ${ }^{19}$ quien atribuye -en gran parte- al criterio temático con el que se organizó la primera edición la fuerte recepción crítica del concepto de "historicismo absoluto" gramsciano. Según el autor, aquella primera organización de los textos carcelarios hizo que la recepción inicial de Gramsci en Italia no pudiera leer el vínculo del concepto de "historicismo absoluto" con el de "terrenalidad del pensamiento". Por lo tanto, inicialmente, el "historicismo absoluto" de Gramsci fue entendido como fruto exclusivo de la influencia de Croce, es decir, como un concepto propio de las filosofías especulativas post-hegelianas. Estas primera interpretaciones influyeron en Louis Althusser, quien al abordar esta idea hizo énfasis en el término "absoluto" para hablar de un esencialismo hegeliano de Gramsci. La crítica althusseriana al historicismo de Gramsci ha trascendido largamente, determinando no sólo la demarcación que ha quedado efectuada entre la tradición althusseriana y la gramsciana, sino también el abandono -por parte de perspectivas materialistas de la filosofía marxista- del problema de la historia o el historicismo en Gramsci. Aquí procuro mostrar que además de la relevancia que ha tenido para las discusiones internas al marxismo del siglo XX, el debate que Althusser entabla con Gramsci arroja luz sobre la cuestión del historicismo y del modelo de temporalidad general que aparece en los Cuadernos.

En el artículo Contradicción y sobredeterminación, escrito en 1962, Althusser da cuenta de lo que entiende por "contradicción sobredetermina-

19. Thomas, P.: The Gramscian cit., p. 244.

Thémata. Revista de Filosofía No62 (2020) pp.: 105-124. 
da" ${ }^{20}$ y reconoce a Gramsci como un precedente clave ${ }^{21}$ para formular dicha noción en contraposición al modelo "ideológico" y "místico" de la "simple contradicción". Althusser cita las reflexiones de Gramsci sobre la tentación mecanicista en la historia del marxismo, considerándolo el único teórico marxista -después de Marx y Lenin- que explora el campo desconocido de la superestructura y a la vez advierte sobre el carácter ideológico y pseudo-religioso del determinismo mecanicista. ${ }^{22}$ Sin embargo, en $1965 \mathrm{Al}$ thusser dicta un seminario sobre El Capital y comienza a definir algunas de sus posiciones en contraposición con ideas gramscianas. ${ }^{23}$ Ese mismo año publica -junto a Étienne Balibar y otros colaboradores- su importante obra Para leer El Capital, compilando muchas de sus notas del seminario. Allí incluye el artículo El marxismo no es un historicismo ${ }^{24}$ en donde se desmarca de toda forma de historicismo, mencionando que considera a Gramsci parte de un conjunto de "revolucionarios humanistas e historicistas" que, a pesar de haber reaccionado frente al dogmatismo de la Segunda Internacional, constituyen una "amenaza" para el marxismo.

el marxismo, desde un punto de vista teórico, no es ni un historicismo, ni un humanismo (...) es, en un mismo movimiento teórico y en virtud de la única ruptura epistemológica que lo fundamenta, un antihumanismo y un antihistoricismo. (...) Sabemos perfectamente en qué circunstancias nació esta interpretación humanista e historicista de Marx (...) Fue primero gracias a la izquierda alemana de Rosa Luxemburgo y de Mehring, y luego, después de la Revolución del 17, gracias a una serie de teóricos entre los cuales algunos se perdieron como Korsch, pero otros desempeñaron un papel importante, como Lukács, y aún más importante, como Gramsci, que los temas del humanismo y del historicismo revolucionarios fueron puestos en escena. Sabemos en qué términos juzgó Lenin este movimiento de reacción "izquierdizante" contra la simpleza mecanicista de la II Internacional: condenando sus fábulas teóricas, su táctica política (...) pero sabiendo reconocer lo que tenía de auténticamente

20. Frente a la pregunta de por qué fue posible la Revolución Rusa y si hubo factores determinantes, Althusser considera al acontecimiento como un producto específico de las circunstancias históricas concretas en las que se desarrolló, y no como resultado de una "pura contradicción" entre Capital y Trabajo. Hace énfasis en la confluencia de una multiplicidad de circunstancias, donde cada una constituye a la vez una acumulación de contradicciones que da lugar a una unidad de -heterogéneas- contradicciones acumuladas resultando en una "ruptura" histórica: la Revolución. Althusser considera que todas esas contradicciones acumuladas provienen de las relaciones de producción, de la superestructura y de la coyuntura internacional. Así define el concepto de "contradicción sobredeterminada": "son aquellas contradicciones que unidas pueden dar lugar a un acontecimiento como la Revolución y que son "inseparables de la estructura del cuerpo social todo entero (...) determinada[s] por los diversos niveles y las diversas instancia de la formación social que ella anima». Althusser, L.: La revolución teórica de Marx. México D.F. / Buenos Aires: Siglo XXI, 2011, p. 81.

21. Cf. Ibid., p. 71.

22. Cf. Ibid., pp. 83-84.

23. Cf. Morfino, V.: "Althusser lector de Gramsci” en Representaciones, Vol. XI, No 1, 2015, p. 44.

24. Althusser, L.: Para leer El Capital. México D.F. / Buenos Aires: Siglo XXI, 2015, p. 130.

Thémata. Revista de Filosofía No62 (2020) pp.: 105-124. 
revolucionario, por ejemplo, en Rosa Luxemburgo y en Gramsci. ${ }^{25}$

Así, y desde un "anti-historicismo teórico", Althusser se opone al "historicismo absoluto" porque lo considera producto de una mala comprensión de El Capital por parte del marxismo en general y de Gramsci en particular. En este punto, es importante recordar que el filósofo francés estaba leyendo -junto con el resto de los primeros intérpretes de la obra carcelaria de Gramsci- al concepto de "historicismo absoluto" en continuidad con el idealismo especulativo de Croce, idealismo que para Althusser impedía pensar en una efectiva y material transformación práctica y material en la historia. ${ }^{26}$

Siguiendo a Vittorio Morfino, ${ }^{27}$ entiendo que para entender en profundidad estos señalamientos althusserianos al "historicismo absoluto" de Gramsci, es fundamental volver en detalle al concepto de "contradicción sobredeterminada". Buscando desacreditar interpretaciones economicistas de la filosofía de Marx, con esta noción Althusser establece una causalidad propia del "todo social estructurado", en la que todos los eventos son determinados por una complejidad de relaciones estructurales:

Marx nos presenta los fenómenos económicos (...) no en la infinidad de un espacio plano homogéneo, sino en una región determinada por una estructura regional e inscripta en un lugar definido de una estructura global; por lo tanto, como un espacio complejo y profundo, inscrito a su vez en otro espacio complejo y profundo. ${ }^{28}$

En pos de pensar este esquema de espacios complejos en el "todo social estructurado", Althusser considera necesario desarrollar un concepto de tiempo histórico que admita para cada nivel de la estructura un ritmo particular -relativamente autónomo con respecto a los demás, aunque dependiente de la totalidad. Althusser sostiene que

el momento privilegiado de transparencia reservado por Hegel para un momento futuro indeterminado fue transferido [por Marx] subrepticiamente a todos los presentes posibles, cada uno de los cuales poseía el "corte de esencia" ${ }^{29} \mathrm{de}$ la contemporaneidad. ${ }^{30}$

Este es el origen de lo que puede entenderse como el modelo de temporalidad plural althusseriano, cuyas implicancias desarrollaré más adelante.

25. Ibíd., pp. 130-131.

26. Cf. Ibid., pp. 142-143.

27. Cf. Morfino, V.: op. cit., p. 49.

28. Althusser, L.: Para leer cit., p. 197.

29. El término original en francés es "coupe d'essence".

30. Cita traducida del inglés. Thomas, P.: The Gramscian cit., p. 4.

Thémata. Revista de Filosofía º62 (2020) pp.: 105-124. 
En este marco, el problema que para Althusser tiene el "historicismo absoluto" gramsciano es la reducción del "todo marxista" al "todo hegeliano" por medio de una identificación -como la que produce Croce- entre los términos filosofía, ciencia e ideología. Aunque por momentos pareciera observar el esfuerzo gramsciano de dejar atrás el carácter especulativo del historicismo de Croce, Althusser sostiene que Gramsci homogeniza todas las prácticas al "historizarlas" en un mismo plano: el de la ideología. ${ }^{31}$ Esto, a ojos althusserianos, impide pensar en los múltiples presentes posibles que existen en el "todo social estructurado". Es decir, para Althusser, en Gramsci el marxismo "se convirtió en una mera forma de autoconciencia del presente que no podía afirmar ser cualitativamente diferente de otras formas de autoconciencia o, de hecho, objetivamente superior a ellas». ${ }^{32}$

A esta reconstrucción es importante agregar que en 1968 Althusser publica una carta -que había enviado a Dal Sasso en diciembre de 1967en donde permite ver que el problema que encuentra en el "historicismo absoluto" de Gramsci es que genera una "amalgama de la ciencia de la historia y de la filosofía bajo la expresión única de "filosofía de la praxis"»; ${ }^{33}$ es decir que, a su juicio, la gravedad de la no-distinción gramsciana entre filosofía y ciencia radica en la pérdida de la especificidad de las prácticas teóricas -léase, tanto de la filosofía marxista como de la ciencia marxista de la historia.

Es por esto que, sintéticamente, es posible afirmar que el rechazo althusseriano al historicismo de Gramsci tiene dos aristas complementarias: por un lado, a criterio de Althusser, Gramsci establece una continuidad -y no una ruptura- con el historicismo crociano, al realizar una "historización" de la filosofía, lo cual constituye -a su juicio- una negación de la historia como la que había operado Hegel. Y por otro lado, Althusser se preocupa por la identificación gramsciana entre teoría e ideología porque considera que lleva inevitablemente a la indistinción entre ciencia y

31. Según Morfino (Morfino, V.: op. cit., p. 51), en 1966 Althusser escribe unas notas tituladas Gramsci $\varphi$ et pol en donde pone de manifiesto que la identificación entre filosofía e ideología en Gramsci consiste -como expliqué previamente- en que no hay diferencia cualitativa entre ambos términos, sino sólo una diferencia cuantitativa. Y si bien parece comprender a qué se estaba refiriendo Gramsci, Althusser le critica en ese texto no haber trabajado lo suficiente la relación entre filosofía y ciencia, ya que la definición gramsciana de filosofía está completamente determinada -según el criterio de Althusser- por su relación con la práctica. El historicismo de Gramsci, para Althusser, está desconectado de la realidad, debido a esta falta de especificidad a la hora de pensar a la filosofía y, por tanto, a la historia de la filosofía y de la teoría en general. Cf. Althusser, L.: "Notes sur la philosophie" en Althusser, L.: Écrits philosophiques et politiques, T. II, París: Stock/Imec, 1995, pp. 299-300. en Morfino V.: op. cit.

32. Cita traducida del inglés. Thomas, P.: The Gramscian cit., p. 5.

33. Althusser, L.: Para leer cit., p. 16.

Thémata. Revista de Filosofía No62 (2020) pp.: 105-124. 
filosofía, y al descrédito de la filosofía como práctica transformadora de la realidad.

\section{Hipótesis sobre el reencuentro entre Gramsci y Althusser en las temporalidades plurales}

Tomando todos estos elementos en consideración, intentaré mostrar aquí que, más allá de las críticas, existe cierta relevancia del pensamiento gramsciano en la historia del trabajo de Althusser en general. Asimismo,

[s]i como dice Althusser, la esencia del trabajo filosófico consiste en la de- marcación, en el desvio (détour) a través de otras posiciones para definir y sostener la propia, me parece que una buena clave de lectura de la posición althusseriana está constituida por el trabajo incesante que él ha hecho sobre Gramsci, trabajo tanto más necesario cuanto más sentía Althusser que en los conceptos de Gramsci se jugaba algo esencial para su propia filosofía. ${ }^{34}$

En términos de coyuntura teórica, y además de la interpretación ya mencionada que el contexto de la primera edición de los Cuadernos hizo sobre la influencia de Croce en Gramsci, es importante tener presente algo que Étienne Balibar relata en una entrevista con Fabio Frosini y Vittorio Morfino: ${ }^{35}$ en la década de 1960 existía una fuerte influencia del pensamiento gramsciano en la línea oficial del Partido Comunista Italiano (PCI) al que Althusser se había opuesto -principalmente- porque le interesaba defender la independencia de la teoría respecto de la práctica política. Considerando esto, es posible pensar que el ataque hacia el "historicismo absoluto" gramsciano haya estado directamente vinculado con cierta intención política, por parte de Althusser, de construir teoría a partir del diálogo y la polémica constante con Gramsci por el interés que muchas de las ideas presentes en los Cuadernos despertaron. Sin embargo, me interesa señalar que el propio Balibar también comenta que esta postura althusseriana de oposición acérrima a la filosofía gramsciana se vio flexibilizada en la década de 1980, cuando Althusser comenzó a construir su "materialismo aleatorio". ${ }^{36}$

Es innegable que los comentarios sobre el "historicismo absoluto" gramsciano pusieron en el mapa a una categoría que, de otra manera, hubiese pasado desapercibida, ya sea porque es mencionada sólo tres veces

34. Morfino, V.: op. cit., p. 63.

35. Frosini, F. y V. Morfino: "Althusser e Gramsci, Gramsci e Althusser: intervista a Etienne Balibar" en Décalages, Vol. 2, Iss. 1, 2016, pp. 1-25.

36. Se refiere a los textos contenidos en Para un materialismo aleatorio. Cf. Althusser, L.: Para un materialismo aleatorio. Madrid: Arena Libros, 2002.

Thémata. Revista de Filosofía No62 (2020) pp.: 105-124. 
en los Cuadernos, o porque no formaba parte del itinerario de los intérpretes canónicos de la obra gramsciana.

El gran mérito de la lectura de Althusser fue precisamente haber dirigido nuestra atención a los temas sobre la no-contemporaneidad en el pensamiento de Gramsci; de hecho, tal vez fue solo la fuerza polémica de la intervención de Althusser lo que finalmente hizo posible leer rasgos del pensamiento de Gramsci que anteriormente parecían ilegibles, por debajo de ese nivel de visibilidad que una tradición interpretativa establecida (el historicismo más croceano que gramsciano del PCI) había permitido. ${ }^{37}$

En línea con las palabras de Peter Thomas ensayo aquí, a modo de conclusión del presente artículo, una demostración de las similitudes que paradójicamente considero existen entre el modo en que Gramsci pensó -desde la "terrenalidad del pensamiento" y desde su propia versión del "historicismo absoluto- el carácter no-contemporáneo del presente, y el modelo de temporalidad plural que el propio Althusser elaboró, primero en relación al concepto de "todo social estructurado", y luego a partir de la construcción del materialismo aleatorio. Considero que, en ambos casos, hay una concepción general de que el tiempo no es lineal ni único como indican las más importantes tradiciones filosóficas de la modernidad, sino que es de carácter plural.

Es importante aclarar que, a grandes rasgos y en términos contemporáneos, ${ }^{38}$ un modelo de temporalidad plural se define por postular la existencia de niveles temporales complejos y relativamente autónomos que se articulan entre sí de maneras aleatorias o contingentes, y nunca de manera lineal, necesaria, única o teleológica. Morfino indica que se trata de una idea que invalida tanto a un modelo de tiempo continuo -a menudo atribuido a Hegel y Engels por presentar a la política como efectuación de una filosofía teleológica de la historia-, como a uno de tiempo discontinuo interrumpible por algún acontecimiento mesiánico rupturista -presente en desarrollos como el de Benjamin. ${ }^{39} \mathrm{~A}$ mi juicio, constituye un punto de encuentro teórico entre Gramsci y Althusser.

Existe una importante diversidad de desarrollos teóricos en torno a la idea general de tiempos plurales. Tempora multa ${ }^{40}$ es una compilación de varias reflexiones marxistas ${ }^{41}$ al respecto. Allí Morfino señala que las

37. Cita traducida del inglés. Thomas, P.: "Gramsci's plural temporalities" en Morfino, V. y Thomas P. (ed.): The Government of Time: Theories of Plural Temporality in the Marxist Tradition, Leiden: Brill Academic Press, 2017, p. 10.

38. Cf. AAVV: Tempora multa. Il governo del tempo. Milán: Mimesis, 2013.

39. Cf. Morfino, V. [En línea]: "La temporalidad plural de la multitud", en Youkali (2007), http://www.youkali.net/youkali4a1Morfino.pdf

40. $C f$. AAVV: op. cit.

41. Si bien no se trata de un debate exclusivo de la tradición marxista, aquí me atendré sola-

Thémata. Revista de Filosofía No62 (2020) pp.: 105-124. 
consecuencias más importantes de aceptar un concepto de temporalidad plural al interior del marxismo son: el abandono definitivo de la idea de sujeto universal que había dominado a gran parte de la tradición, y la renuncia a los modelos de desarrollo preestablecidos que proyectan una realidad futura particular sobre otras que son diferentes. Asimismo, el autor comenta que el problema de la temporalidad plural aparece ya con Marx cuando se observa el desarrollo diferencial -y en distintos niveles- de las temporalidades en Francia, Inglaterra y Alemania durante el siglo XIX . Luego de Marx, Ernst Bloch ${ }^{42}$ y Gramsci -de manera casi simultánea-continúan con la crítica explícita de un tiempo estable y único. Según Morfino, sólo Gramsci logra elaborar en los Cuadernos de la cárcel un análisis -desde su desarrollo sobre la cuestión del historicismo y del presente no-contemporáneo- que reconoce la naturaleza esencialmente "fracturada" del tiempo. Althusser, al considerar la idea gramsciana de "historicismo absoluto" heredera de Hegel y Croce, no reconoce -como mostré anteriormente - este aspecto del pensamiento de Gramsci, y por eso dialoga sólo con Bloch cuando afirma que existe un tiempo particular para cada nivel del "todo social estructurado".

Para profundizar en el abordaje del problema del tiempo plural en Gramsci, me interesa señalar un doble movimiento conceptual del autor: la identificación, por un lado, de filosofía con ideología -como señalé previamente- en estrecho vínculo con la "reinvención de la inmanencia" que realiza en los Cuadernos al establecer un nexo intrínseco entre teoría y práctica; y la afirmación, por otro lado, de que el presente no es más que una construcción política de las clases hegemónicas. Para Gramsci es importante contemplar la "no-presencia" del presente respecto a sí mismo, es decir, entender que el presente no se encuentra unificado a priori y que la contemporaneidad no es más que una construcción ilusoria. ${ }^{43} \mathrm{Si}$ bien no es posible -por cuestiones de espacio- desarrollar aquí con más detalle las implicancias de esta idea, me limito a señalar que, detrás de la noción gramsciana del "presente no-contemporáneo" existe un modelo de tiempos plurales y heterogéneos (diferentes pasados, presentes y futuros) que conviven de manera caótica hasta que son ordenados por la

mente a esta línea de desarrollo con el objetivo de aportar elementos al análisis de los conceptos de Gramsci y Althusser. Para una breve recapitulación de los aportes de otras tradiciones al respecto. Cf. Thomas, P.: "Gramsci's plural..." cit.

42. Morfino advierte que, si bien Bloch señala que hay contradicciones que hacen que haya una no-contemporaneidad tanto en la estructura como en la superestructura, en última instancia considera que la pluralidad del tiempo es sólo una contradicción momentánea y que sí existe un tiempo fundamental que define la contemporaneidad y la no-contemporaneidad -que es la temporalidad del comunismo. Cf. Morfino, V.: "La temporalidad..." cit.

43. Cf. Gramsci, A.: op. cit.: C8 §232; Thomas, P.: The Gramscian cit., p. 282.

Thémata. Revista de Filosofía No62 (2020) pp.: 105-124. 
construcción política o -en sus términos- hegemónica. ${ }^{44}$ Esto quiere decir que para Gramsci no puede haber una unidad del presente respecto de sí mismo dada a priori: es función de la hegemonía lograr unidad entre lo que inicialmente se encuentra fragmentado y diversificado. El presente es, en este desarrollo gramsciano, un producto de carácter político que como tal no tiene más valor que el de responder al sentido que buscó imprimirle la clase dominante al instituirlo. En el marco de este modelo de temporalidades plurales que es posible reconocer en Gramsci, la historización de la realidad que plantea al reformular concepto de "historicismo absoluto" en términos de inmanencia entre teoría y práctica, procura mostrar que el presente se trata siempre de una construcción contingente, y que no podría distinguirse del ámbito de la práctica.

A diferencia de -pero, a la vez, en sintonía con- la forma en que aparece la temporalidad plural en Gramsci, Althusser no considera que exista un vínculo inmanente entre teoría y práctica porque sostiene que la teoría es una práctica más -entre muchas otras, presentando cada una una temporalidad específica- de las que conforman el "todo social estructurado". Cada una de esas prácticas, como ya mencioné anteriormente, constituye -para el Althusser de la década de 1960- un ritmo o un tiempo particular, y por tanto la idea general de tiempo histórico debe, según el autor, adaptarse a dicha heterogeneidad temporal. En 1982 -y particularmente en La corriente subterránea del materialismo del encuentro- ${ }^{45}$ Althusser enfatiza el carácter plural del tiempo al construir de un materialismo aleatorio y contingente, donde no hay lugar para formas lineales o teleológicas del tiempo y la historia.

Desde una perspectiva contemporánea, y resaltando los modos en que estos autores pensaron la no-linealidad del tiempo, la distancia que tomó Althusser respecto a Gramsci parece acortarse ya que parece existir en ambos la intención de pensar en un modelo de temporalidad complejo y plural. Si se asume este punto de vista, el desencuentro entre las tradicio-

44. Esta hipótesis de Thomas -también sostenida por Morfino (Cf. AAVV: op. cit., p. 9) y Frosini (Cf. AAVV: op. cit., p. 225) - sobre la no-contemporaneidad del presente en Gramsci como modo de aparición de la pluralidad temporal constituye un problema solo incipientemente trabajado a partir de los textos de Gramsci, debido a que no se encuentra planteada de manera explícita ni repetitiva en los Cuadernos de la cárcel. El argumento principal de Thomas es que, en los textos carcelarios, esta constitución plural del tiempo se permite entrever en el tratamiento de cuatro grandes dimensiones de la realidad: la personalidad, la constitución de los Estados-nación, el lenguaje y la lucha de clases (Cf. Thomas, P.: "The Plural Temporalities of Hegemony” en Rethinking Marxism, 29:2, 2017, pp. 281-302). Para un análisis más acabado de esta cuestión, también ( $C f$. Thomas, P.: The Gramscian cit.).

45. Althusser, L. "La corriente subterránea del materialismo del encuentro", en Althusser, L.: Para un materialismo aleatorio. Madrid: Arena Libros, 2002, p. 31.

Thémata. Revista de Filosofía No62 (2020) pp.: 105-124. 
nes althusseriana y gramsciana es una conversación abierta, y comienza a dar señales de parecerse más a un encuentro que a una polémica.

Según Morfino, ${ }^{46}$ Althusser y Gramsci coinciden en pensar el carácter plural del tiempo no como una condición momentánea -como lo entendía Bloch-, sino como la estructura inmodificable de la temporalidad misma. Para Martín Cortés, la similitud consiste en que ambos entienden al presente como dominación. ${ }^{47}$ Cuando se muestra "sin fisuras", unívoco y progresivo, el presente se vuelve ideológico - para Althusser- o hegemónico - para Gramsci- porque esconde la posibilidad de otras alternativas. Y frente a eso, revelar la heterogeneidad del tiempo es rescatar su carácter político.

En conclusión, considero que existe, tanto en Gramsci como en Althusser, una importante crítica de las filosofías especulativas y totalizantes. El concepto gramsciano de "historicismo absoluto" es parte de esa crítica, y como tal, está lejos de ser un concepto que reduce -como sostuvo, en sintonía con su contexto, Althusser- el marxismo al hegelianismo. Más bien, se acerca a un modelo de temporalidad plural, aunque diferente al que aparece en las reflexiones del propio Althusser. Con "historicismo absoluto" Gramsci refiere a una radicalización del carácter histórico -y como tal, práctico- de todos los aspectos de la realidad, dando cuenta de que no es posible establecer a priori una temporalidad unificada; Althusser, por su parte, niega también que el tiempo sea una sola línea, afirmando primero que cada nivel del "todo social" presenta su propia temporalidad, y luego que no hay teleología histórica posible, sino pura contingencia generada por el encuentro aleatorio de elementos heterogéneos. Es así que, a pesar de las evidentes diferencias tanto contextuales como conceptuales, en ambas perspectivas se presenta, con claridad, una oposición a la concepción especulativa del tiempo y la historia, y una apuesta por complejizar el abordaje materialista del problema de lo temporal.

\section{Referencias bibliográficas}

Sobre la sigla utilizada para citar los Cuadernos de la cárcel:

$\mathrm{Al}$ referirme a la obra de Gramsci, Cuadernos de la cárcel, editada en

46. Según Marcelo Starcenbaum, Vittorio Morfino es el autor que más claramente ha logrado mostrar las posibles intersecciones entre Gramsci y Althusser en función de los aspectos más bien políticos de sus respectivos desarrollos filosóficos. Cf. Starcenbaum, M.: "Gramsci y Althusser: intersecciones del marxismo contemporáneo”, en Karczmarczyk, P., Romé, N., y M. Starcenbaum (coord.): Actas del Coloquio Internacional 50 años de Lire le Capital, Universidad Nacional de La Plata, 2017, p. 602.

47. Cf. Cortés, M.: "Asincronías. Notas sobre el tiempo y la política, entre Althusser y el marxismo latinoamericano" en Revista Demarcaciones, No 6, 2018, p. 1.

Thémata. Revista de Filosofía No62 (2020) pp.: 105-124. 
México D.F por Era en 1981, utilizo la modalidad de indicar el Cuaderno del que proviene la cita mediante la letra "C", y el apartado en particular en la que está contenida, por medio del símbolo §. Por caso, cuando me refiero al apartado 16 del Cuaderno 7, cito: Gramsci, 1981, C7, §16. De esta manera, la cita puede rastrearse en todas las ediciones -en cualquier idioma- provenientes de la edición crítica original de los Cuadernos a cargo del Instituto Gramsci de Turín (1975).

AAVV: Tempora multa. Il governo del tempo. Milán: Mimesis, 2013.

Althusser, L.: "Notes sur la philosophie" en Althusser, L.: Écrits philosophiques et politiques, T. II, París: Stock/Imec, 1995, pp. 299-300.

Althusser, L.: Para un materialismo aleatorio. Madrid: Arena Libros, 2002.

Althusser, L.: La revolución teórica de Marx. México D.F. / Buenos Aires: Siglo XXI, 2011.

Althusser, L.: Para leer El Capital. México D.F. / Buenos Aires: Siglo XXI, 2015.

Bujarin, N.: Teoría del materialismo histórico. Ensayo popular de sociología marxista. Córdoba: Ediciones Pasado y Presente, 1972.

Cortés, M.: "Asincronías. Notas sobre el tiempo y la política, entre Althusser y el marxismo latinoamericano" en Revista Demarcaciones, No 6, 2018, pp 1-8.

Fernández Liria, P.: "Posfacio" en Althusser, L.: Para un materialismo aleatorio. Madrid: Arena Libros, 2002.

Francioni, G.: L'officina gramsciana, Napoli: Bibliopolis, 1984.

Frosini, F.: "Il divenire del pensiero nei «Quaderni Del Carcere» di Antonio Gramsci. Appunti per una rilettura" en Critica marxista, No 3-4, 2000, pp. 108-120.

Frosini, F. y V. Morfino: "Althusser e Gramsci, Gramsci e Althusser: intervista a Etienne Balibar" en Décalages, Vol. 2, Iss. 1, 2016, pp. 1-25.

Gramsci, A.: Cuadernos de la Cárcel, México D.F.: Era, 1981.

Marx, K.: "Tesis sobre Feuerbach" en Marx, K.: Antología. Buenos Aires: Siglo XXI, 2014.

Morfino, V. [En línea]: "La temporalidad plural de la multitud”, en Youkali (2007), http://www.youkali.net/youkali4a1Morfino.pdf 
Morfino, V.: "Althusser lector de Gramsci" en Representaciones, Vol. XI, No 1, 2015.

Starcenbaum, M.: "Gramsci y Althusser: intersecciones del marxismo contemporáneo", en Karczmarczyk, P., Romé, N., y M. Starcenbaum (coord.): Actas del Coloquio Internacional 50 años de Lire le Capital, Universidad Nacional de La Plata, 2017, pp. 587-604.

Thomas, P.: "Historicism, absolute" en Historical Materialism 15, 2007.

Thomas, P.: The Gramscian Moment: Philosophy, Hegemony and Marxism, Leiden-Boston: Brill, 2009.

Thomas, P.: "Gramsci's plural temporalities" en Morfino, V. y Thomas P. (ed.): The Government of Time: Theories of Plural Temporality in the Marxist Tradition, Leiden: Brill Academic Press, 2017, pp.174-209.

Thomas, P.: "The Plural Temporalities of Hegemony" en Rethinking Marxism, 29:2, 2017, pp. 281-302. 
